\title{
Susceptibility of Cold-Climate Wine Grape Cultivars to Downy Mildew, Powdery Mildew, and Black Rot
}

\author{
David S. Jones and Patricia S. McManus, Department of Plant Pathology, University of Wisconsin, Madison, 53706
}

\begin{abstract}
Lack of knowledge regarding the susceptibility of cold-climate hybrid wine grape cultivars may be leading to the overuse of fungicides and underutilization of plant host resistance to combat disease in the northern United States. To provide new insights on diseases of cold-climate cultivars and to update management recommendations, disease was evaluated in three vineyards containing eight cultivars that were not sprayed with fungicides in 2015 and 2016. Disease severity or incidence of downy mildew (Plasmopara viticola), powdery mildew (Erysiphe necator), and

black rot (Guignardia bidwellii) were measured from bud break until 2 weeks after harvest. Cold-climate cultivars ranged widely in susceptibility to different diseases and, although several cultivars were relatively resistant to two diseases, no cultivar was highly resistant to all three diseases Additionally, a difference between foliar and fruit susceptibility for all three diseases was noted in several cultivars. These data provide a foundation for developing low-spray and certified organic disease management strategies for cold-climate wine grape cultivars based on susceptibility to disease.
\end{abstract}

Wine grape cultivation has historically focused on the European wine grape, Vitis vinifera. Although $V$. vinifera cultivars produce notable wines, they lack the cold tolerance needed to survive winter temperatures below -15 to $-20^{\circ} \mathrm{C}$. This lack of cold tolerance in wine grape cultivars has limited large-scale production to regions where $V$. vinifera reliably survives winter temperatures. Over the past two decades, however, both public and private grape breeders have released several "cold-climate cultivars" that are crosses of cold-hardy native American grape species (e.g., V. riparia, V. aestivalis, V. cinerea, and V. labrusca) with the European wine grape. The cold-climate cultivars can tolerate winter temperatures of -16 to $-37^{\circ} \mathrm{C}$ and produce high-quality wine. Although $V$. vinifera and hybrids have been grown for decades in parts of the northeastern United States where winter temperatures are moderated by lakes, the introduction of the newer cold-climate cultivars has resulted in a rapid expansion of the wine grape industry into areas of the Upper Midwest, Great Plains, and Northeast, where winter temperatures are lethal to V. vinifera (Tuck and Gartner 2013). As of 2011, the cold-climate wine grape industry accounted for nearly 400 ha and contributed over $\$ 400$ million and 12,000 jobs annually to the economies of states in those regions, with further economic impact predicted as newly planted vineyards mature (Tuck and Gartner 2013). A survey in 2012 revealed that over $60 \%$ of vineyards in these regions had been established in the previous 15 years, and $82 \%$ of respondents planned on further expanding their businesses (Tuck and Gartner 2013). Growers surveyed also rated disease as one of the most significant threats to their businesses (Tuck and Gartner 2013). Downy mildew (Plasmopara viticola), powdery mildew (Erysiphe necator), and black rot (Guignardia bidwellii) are particularly widespread diseases that can reduce yield. The season-long use of fungicides to manage these diseases is expensive, and carries risks to the health of applicators, consumers, and the environment. A more recent survey reported a $63 \%$ increase in coldclimate grape acreage since 2011 and that further expansion is expected among existing businesses in coming years (Gartner 2016). This continuing growth trend underscores the need for more knowledge of diseases and host resistance in cold-climate cultivars.

Corresponding author: P. S. McManus; E-mail: pmcmanus@wisc.edu

Accepted for publication 13 April 2017.

C 2017 The American Phytopathological Society
In the Upper Midwest, wild grape species such as $V$. riparia are endemic, and high humidity and summer rains favor disease development; therefore, economically challenging grape pathogens are likely to be present in most regions where commercial vineyards are established. Although previous efforts have been made to rate and categorize disease susceptibility of cold-climate cultivars (Bordelon et al. 2016), we are aware of no such studies performed in vineyards in which cultivar blocks were replicated, randomized, and left not sprayed with fungicides. The objectives of this research were to determine (i) the relative susceptibility of commercially important cold-climate cultivars to downy mildew, powdery mildew, and black rot; and (ii) whether foliage and fruit on a given cultivar differ in disease susceptibility, because this distinction may have significant implications for development of reduced-spray programs. Experiments were conducted at two locations over two growing seasons with cultivars that collectively account for approximately $58 \%$ of cold-climate wine grape acreage (Gartner 2016). Based on the results of this study, the use of host resistance to reduce fungicide inputs in coldclimate wine grape production is discussed.

\section{Materials and Methods}

Field sites. Trials were conducted in 2015 and 2016 at the West Madison Agricultural Research Station in Verona, WI (WMARS, United States Department of Agriculture [USDA] zone 5a) and the Peninsular Agricultural Research Station in Sturgeon Bay, WI (PARS, USDA zone 5 b). These two locations represent significant regions for cold-climate viticulture in Wisconsin. Each site had a vineyard, designated WMARS and PARS 1 consisting of 200 vines (eight cultivars on their own roots $x$ five replicates [randomized complete block design] $\times$ five vines per replicate) established in 2012. White grape cultivars at each site were 'Brianna', 'Frontenac gris', 'La Crescent', and 'LaCrosse' and red grape cultivars at each site were 'Frontenac', 'Marquette', 'St. Croix', and 'Valiant'. Valiant was previously reported to be highly susceptible to downy mildew, powdery mildew, and black rot (Smiley et al. 2015) and was included in this study as a disease indicator. An additional vineyard at PARS, designated PARS 2, was included in the study in 2016, and consisted of 96 vines (six cultivars on their own roots $\times$ four replicates [randomized complete block design] $\times$ four vines per replicate) established in 2008. The cultivars in this vineyard were Brianna, Frontenac, Frontenac gris, La Crescent, LaCrosse, and Marquette. No fungicides were applied to WMARS and PARS 1 during either growing season. Likewise, when PARS 2 was added to the study in 2016, fungicides were withheld. Aside from the absence of fungicide applications, the vineyards were managed according to conventional practices 
(Bordelon et al. 2016). Winter spur pruning reduced the number of buds to three buds per established spur, and shoots were thinned in the spring to three per established spur. Black rot mummies were removed in the dormant season during annual pruning and dropped to the ground with the pruned wood. All material dropped between rows was flail chopped in the early spring before bud break. Vines were hedged as needed, suckers were removed, and bird netting was used to prevent damage during berry ripening. Insecticides were applied as needed at both sites to control grape phylloxera, grape berry moth, and Japanese beetle. All vines were trained in the vertical shoot positioning system at the time of establishment. Daily high and low temperatures and rainfall were measured at WMARS with a Spectrum WatchDog 1000 Series Micro Station (Spectrum Technologies, Inc., Aurora, IL) and at PARS with a CR 1000 Measurement and Control Datalogger (Campbell Scientific, Logan, UT).

Disease assessment. Beginning when leaves unfolded in the spring, all vineyards were scouted at least once per 2-week period by the same researcher for the duration of the growing season in both 2015 and 2016, ending 2 weeks after harvest. The three diseases of interest had been reported previously at WMARS and PARS; therefore, no inoculum was added artificially. In 2015, the severity of downy mildew, powdery mildew, and black rot was rated on three adjacent vines per replicate using a visual scale of 1 to 4 that encompassed the whole canopy and did not distinguish between leaves and fruit. A rating of 1 indicated no disease (0\%), a rating of 2 indicated light disease (1 to $25 \%$ of leaf and cluster area showing symptoms or signs), a rating of 3 indicated moderate disease (26 to $50 \%$ of leaf and cluster area showing symptoms or signs), and a rating of 4 indicated severe disease $(>50 \%$ of leaf and cluster area showing symptoms or signs). In addition to the overall assessment of leaves and fruit combined, we separately estimated downy mildew severity on clusters (percentage of fruit cluster area showing symptoms or signs) on all cultivars using a scale of 0 to $100 \%$ on 13 July at WMARS and 14 August at PARS 1 in 2015.

In 2016, disease was rated separately on leaves and fruit clusters. The severity of downy mildew, powdery mildew, and black rot on leaves was rated on three adjacent vines per replicate with the same scale used in 2015. Downy mildew severity on fruit clusters (percentage of fruit cluster area showing symptoms or signs) was estimated on a scale of 0 to $100 \%$ on 13 July and 10 August at WMARS and 14 July and 11 August at PARS 1 and PARS 2. The percentage of fruit clusters affected by powdery mildew (incidence) in 2016 was determined by counting all clusters on three adjacent vines per replicate on 10 August and 6 September at WMARS and 12 August and 8 September at PARS 1 and PARS 2 . The percentage of fruit clusters affected by black rot (incidence) was determined by counting all clusters on three adjacent vines per replicate, and the percentage of cluster area showing symptoms or signs (severity) was estimated on a scale of 0 to $100 \%$ on 15 August at WMARS and 20 August at PARS 1 and PARS 2.

Data analysis. Data were subjected to statistical analysis using SAS Statistical Software (version 9.4; SAS Institute Inc., Cary, NC). Data from each of the vineyards were analyzed separately for each year and each rating date. For data collected as ratings of 1 to 4 , the SAS RANK procedure was used to create a set of ranked data points. A nonparametric one-way analysis of variance (ANOVA) was applied to the data generated by the RANK procedure (this procedure is equivalent to the Kruskal-Wallis $k$-sample test). For data collected on a 0 to $100 \%$ scale, one-way ANOVA was performed using PROC GLM. Least significant difference tests were conducted for each date to determine significant differences among cultivars in the severity or incidence of each disease.

\section{Results}

Downy mildew. In 2015, severity of downy mildew was significantly different $(P<0.05)$ among cultivars on 13 of 17 rating dates at WMARS and 9 of 16 rating dates at PARS 1 (Fig. 1A and B). In general, disease was more severe and developed earlier in the season at WMARS than at PARS 1. Valiant, the indicator cultivar, had severe foliar and fruit damage in 2015 and was the only cultivar that had fruit visibly damaged by downy mildew, with $>80 \%$ of fruit cluster area affected at both WMARS and PARS 1 (data not shown). Downy mildew severity was high on LaCrosse leaves at WMARS and PARS 1. Downy mildew severity was high on La Crescent leaves at WMARS and moderate at PARS 1 in 2015, but disease developed later in the season than it did on Valiant or LaCrosse. All three of these cultivars were defoliated by downy mildew by the end of the season, a response that was not recorded on the other five cultivars. Downy mildew severity was moderate to high on St. Croix, Brianna, Frontenac, and Frontenac gris leaves at WMARS and low at PARS 1 in 2015. Downy mildew severity was very low on Marquette leaves at WMARS and PARS 1 in 2015. In spite of abundant inoculum produced on nearby vines of other cultivars, sporulating downy mildew lesions were not observed on Marquette at either site in 2015. However, pale yellow lesions resembling "oil-spot" symptoms of downy mildew were observed on older foliage of Marquette near the end of the growing season.

In 2016, severity of downy mildew on foliage was significantly different $(P<0.05)$ among cultivars on 11 of 17 rating dates at WMARS, 8 of 13 rating dates at PARS 1 , and 8 of 13 rating dates at PARS 2 (Fig. $1 \mathrm{C}, \mathrm{D}$, and E). Downy mildew severity was high on both leaves and fruit clusters of Valiant. As in 2015, Valiant was the only cultivar that had fruit visibly damaged by downy mildew, with $>80 \%$ of fruit cluster area affected at both WMARS and PARS 1 (data not shown). Downy mildew severity was high on leaves of LaCrosse and La Crescent at WMARS, PARS 1, and PARS 2. As in 2015, these cultivars were defoliated by the end of the season. Downy mildew severity was high on leaves of St. Croix at both WMARS and PARS 1 in 2016, and the cultivar was defoliated by the end of the season at WMARS. Downy mildew severity was high on leaves of Brianna at WMARS and moderate at PARS1 and PARS 2 but Brianna was not prematurely defoliated. Downy mildew severity was low on leaves of Frontenac and Frontenac gris at WMARS, PARS 1, and PARS 2 in 2016. Light sporulation was observed on both cultivars late in the season, particularly on older leaves. Downy mildew severity was low on leaves of Marquette at WMARS, PARS 1, and PARS 2. Light sporulation occurred sporadically on Marquette foliage at growing tips, and oil-spot lesions were observed on older leaves near the end of the growing season.

Powdery mildew. In 2015, severity of powdery mildew was significantly different $(P<0.05)$ among cultivars on 6 of 17 rating dates at WMARS and 7 of 16 rating dates at PARS 1 (Fig. 2A and B). Powdery mildew severity was low on all eight cultivars at WMARS in 2015. At PARS 1, powdery mildew severity was high on all cultivars except La Crescent and Valiant. Powdery mildew severity was moderate on La Crescent and low on Valiant. Although our ratings did not quantify disease on leaves versus fruit in 2015 , differences were observed in several cultivars.

In 2016, severity of powdery mildew on foliage was significantly different $(P<0.05)$ among cultivars on 2 of 17 rating dates at WMARS, 7 of 13 ratings dates at PARS 1 , and 7 of 13 rating dates at PARS 2 (Fig. 2C, D, and E). Powdery mildew severity was low on Frontenac, Frontenac gris, and Marquette, and the disease was not observed on other cultivars in 2016 at WMARS. Powdery mildew severity was moderate to high on Brianna, Frontenac, Frontenac gris, and Marquette and low on La Crescent, LaCrosse, St. Croix, and Valiant at PARS 1 and PARS 2.

Foliage and fruit clusters were rated separately for powdery mildew in 2016. No powdery mildew was observed on fruit clusters at WMARS in 2016. At PARS 1, powdery mildew incidence on clusters was moderate to high on Brianna, Frontenac, and Frontenac gris (Fig. 3A and B). Powdery mildew incidence on clusters was low on La Crescent, LaCrosse, Marquette, and St. Croix, and powdery mildew was not observed on clusters of Valiant. At PARS 2, powdery mildew incidence on clusters was moderate to high on Brianna, Frontenac, and Frontenac gris (Fig. 3C and D). Powdery mildew incidence on clusters was low on LaCrosse, and powdery mildew was not observed on clusters of La Crescent and Marquette. Powdery mildew was observed primarily on the rachises of La Crescent, Frontenac, Frontenac gris, Marquette, and St. Croix, whereas disease was observed on both berries and rachises of Brianna and LaCrosse.

Black rot. In 2015, severity of black rot was significantly different $(P<0.05)$ among cultivars on 11 of 17 rating dates at WMARS and 8 of 16 rating dates at PARS 1 (Fig. 4A and B). Black rot severity was 
low on all cultivars at WMARS in 2015, with slightly higher ratings on Brianna and Marquette. Black rot severity was low on all cultivars at PARS 1 in 2015, with slightly higher ratings on Frontenac.

In 2016, black rot severity on foliage was significantly different $(P<0.05)$ among cultivars on 13 of 17 rating dates at WMARS, 9 of 13 rating dates at PARS 1 , and 9 of 13 rating dates at PARS 2
(Fig. 4C, D, and E). At WMARS, black rot severity on leaves was moderate on Marquette and Valiant and low on Brianna, La Crescent, LaCrosse, Frontenac, Frontenac gris, and St. Croix. At PARS 1, black rot severity on leaves was high on Valiant; moderate on LaCrosse, Frontenac, Frontenac gris, Marquette, and St. Croix; and low on Brianna and La Crescent. At PARS 2, black rot severity on leaves



B

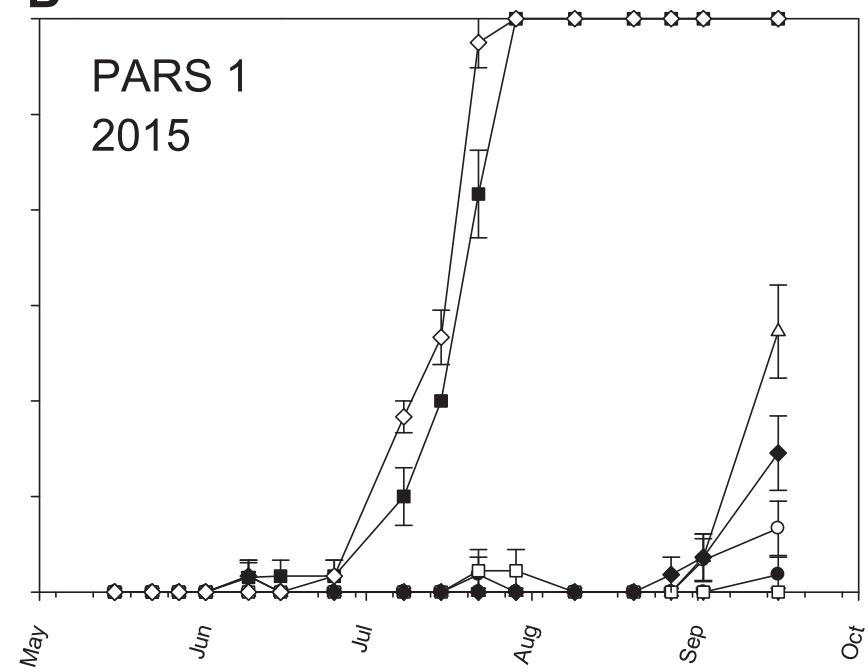

C
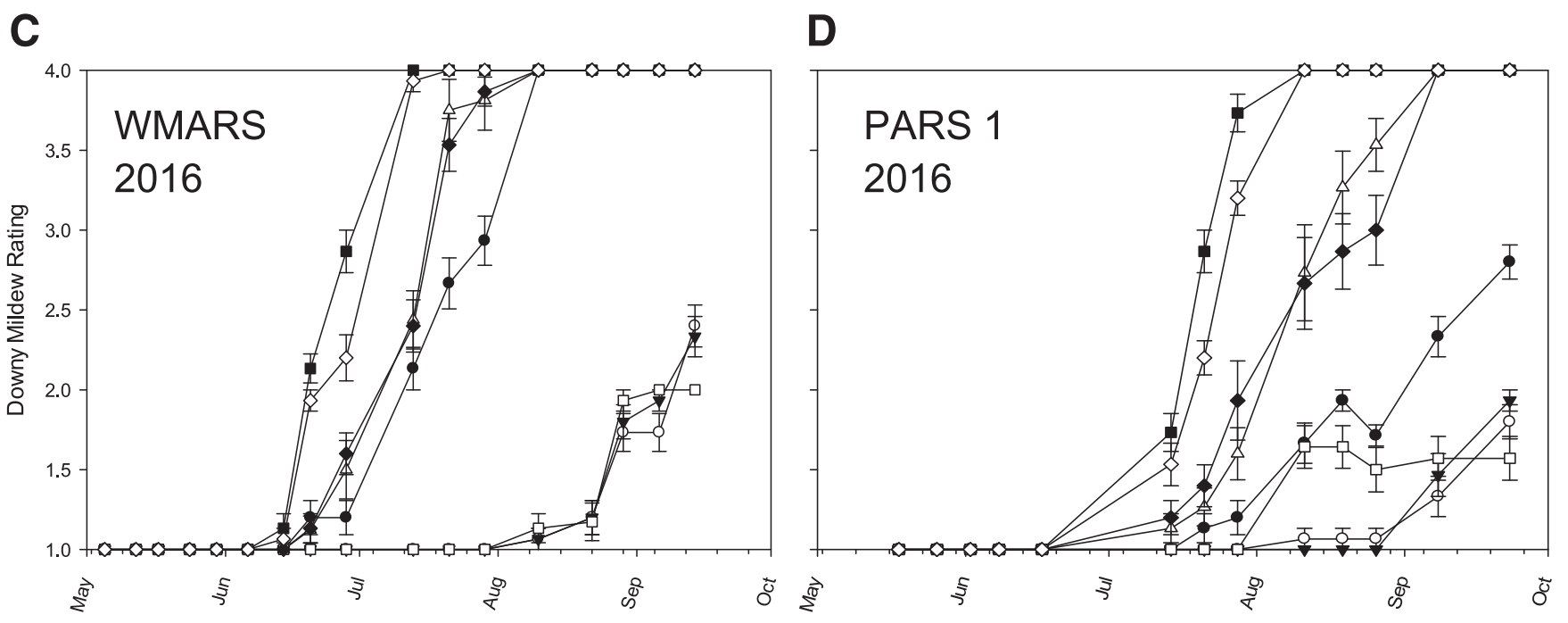

E


Fig. 1. Downy mildew severity ratings at WMARS, PARS 1, and PARS 2 in 2015 (A, B) and 2016 (C, D, E). In 2015, ratings were based on appearance of leaves and fruit clusters. In 2016, ratings were based on appearance of leaves only. 
was low on Marquette, Brianna, Frontenac, Frontenac gris, La Crescent, and LaCrosse.

Black rot incidence on fruit clusters generally paralleled trends in severity in all three vineyards (Fig. 5). At WMARS, Marquette had the highest incidence of black rot on clusters, at approximately $40 \%$, and Valiant had the second highest incidence, at approximately
20\% (Fig. 5A). Disease severity was greatest on Marquette and Valiant, averaging approximately $30 \%$ of cluster area affected on each cultivar (Fig. 5B). Incidence of black rot on clusters on other cultivars was less than $5 \%$, and severity ranged from about 5 to $20 \%$. At PARS 1 , incidence of cluster damage was highest on Valiant, at $84 \%$ (Fig. 5C). Frontenac, Frontenac gris, LaCrosse, and Marquette averaged
A

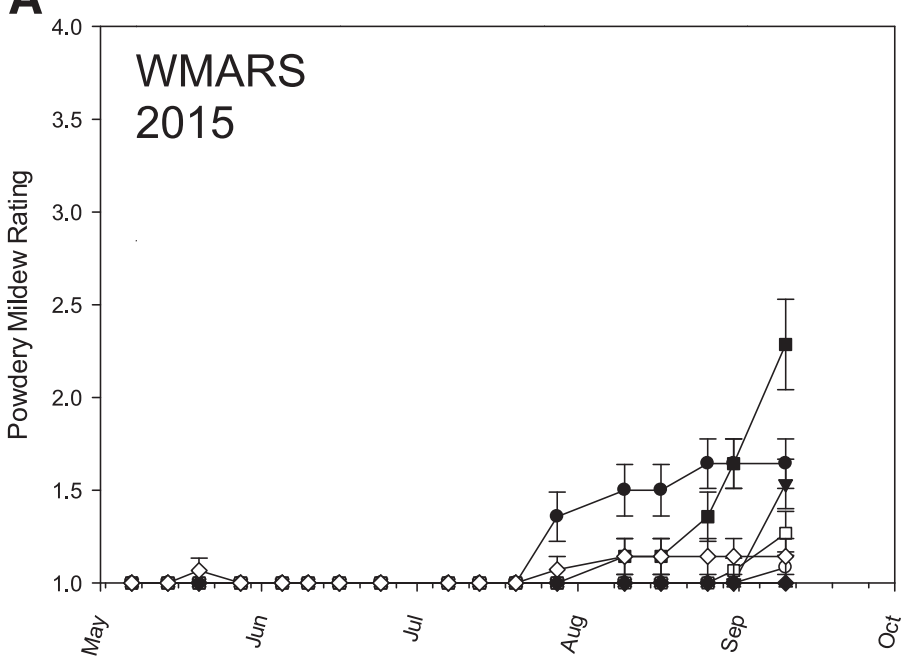

C

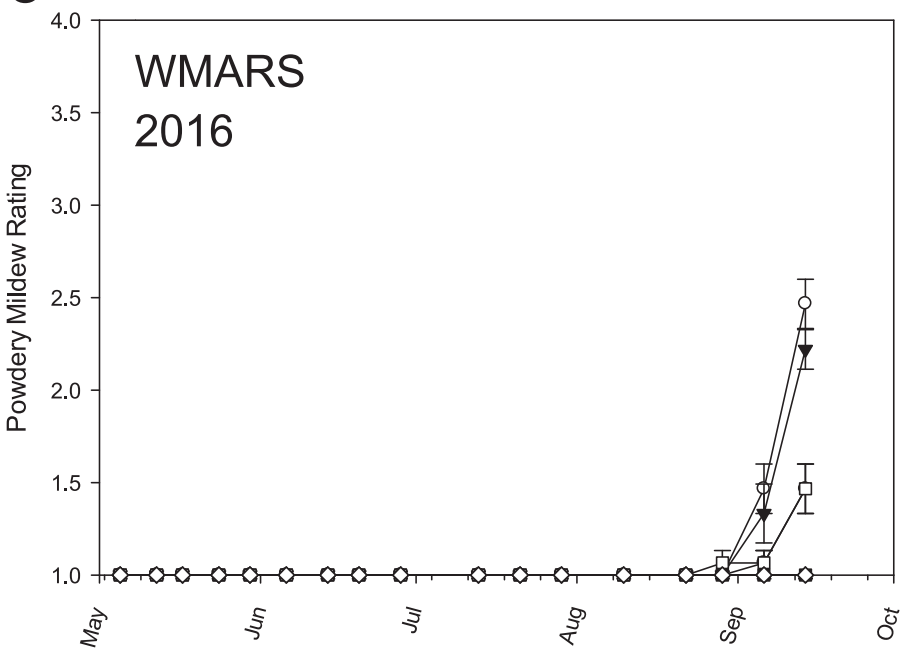

E

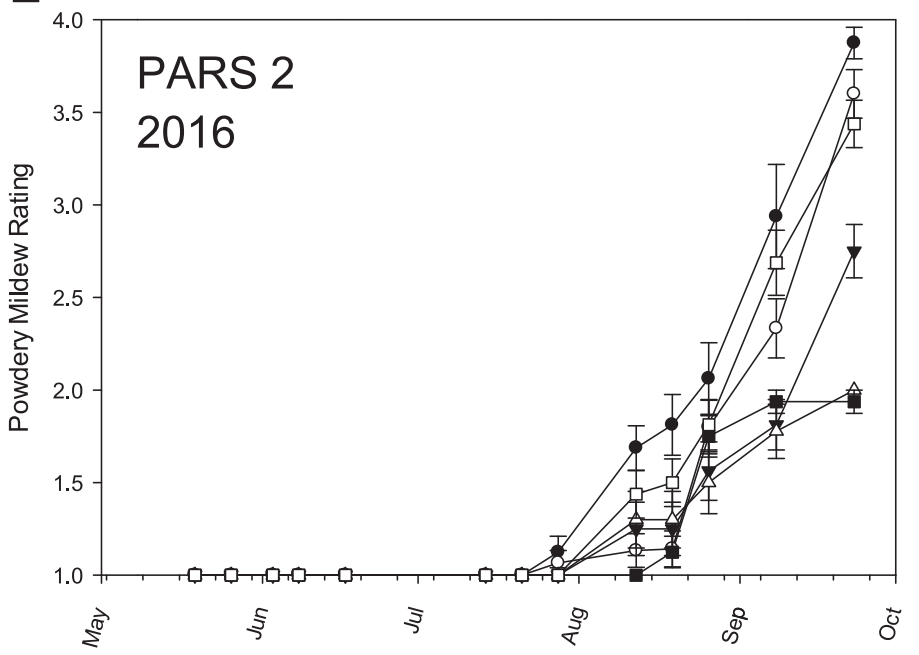

B

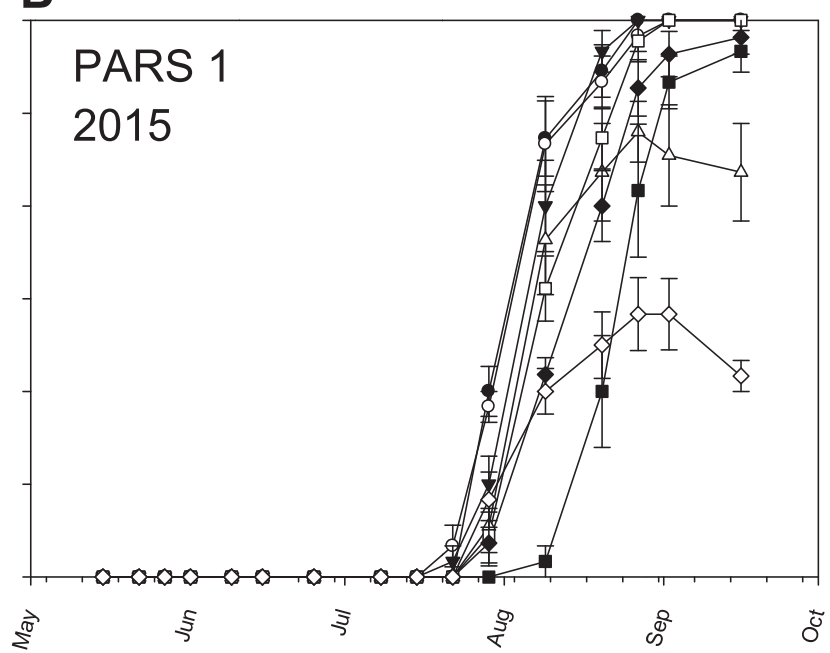

D



Fig. 2. Powdery mildew severity ratings at WMARS, PARS 1, and PARS 2 in 2015 (A, B) and 2016 (C, D, E). In 2015, ratings were based on appearance of leaves and fruit clusters. In 2016, ratings were based on appearance of leaves only. 
between 25 and $45 \%$ of clusters with black rot, whereas Brianna, La Crescent, and St. Croix averaged less than $20 \%$ of clusters with black rot. Disease severity was greatest on Valiant, with about $60 \%$ of cluster area affected (Fig. 5D). Disease severity was approximately 25 to $45 \%$ on Frontenac, Frontenac gris, LaCrosse, and Marquette and approximately $20 \%$ or less on Brianna, La Crescent, and St. Croix. At PARS 2, Marquette and Frontenac gris had the highest incidence of black rot on clusters, at approximately 15 to $20 \%$ (Fig. 5E). Incidence of black rot on clusters on Brianna, La Crescent, LaCrosse, and Frontenac was less than $10 \%$. Disease severity was greatest on Marquette and Frontenac gris at approximately $30 \%$ of cluster area affected (Fig. 5F). Disease severity was approximately $20 \%$ on LaCrosse and less than $20 \%$ on Brianna, La Crescent, and Frontenac.

Weather at WMARS and PARS. WMARS had more frequent and generally heavier rainfall than PARS in 2015 (Fig. 6A and B).
In 2016, both sites had frequent rainfall (Fig. 6C and D). Rain events occurred at least once per week from bud break through harvest at both sites in 2016 .

\section{Discussion}

We report here the relative disease susceptibility of popular coldclimate wine grape cultivars in multiple randomized field trials over two growing seasons. The low susceptibility to downy mildew, powdery mildew, or black rot that was observed in several cultivars sets the stage for development of reduced-spray and organic production strategies for the cold-climate wine industry in the northern United States. Distinctions between foliar and fruit susceptibility to disease in these cultivars will provide additional flexibility as these strategies are developed. Avoidance of highly susceptible cultivars, particularly among growers wishing to minimize fungicide use, will be
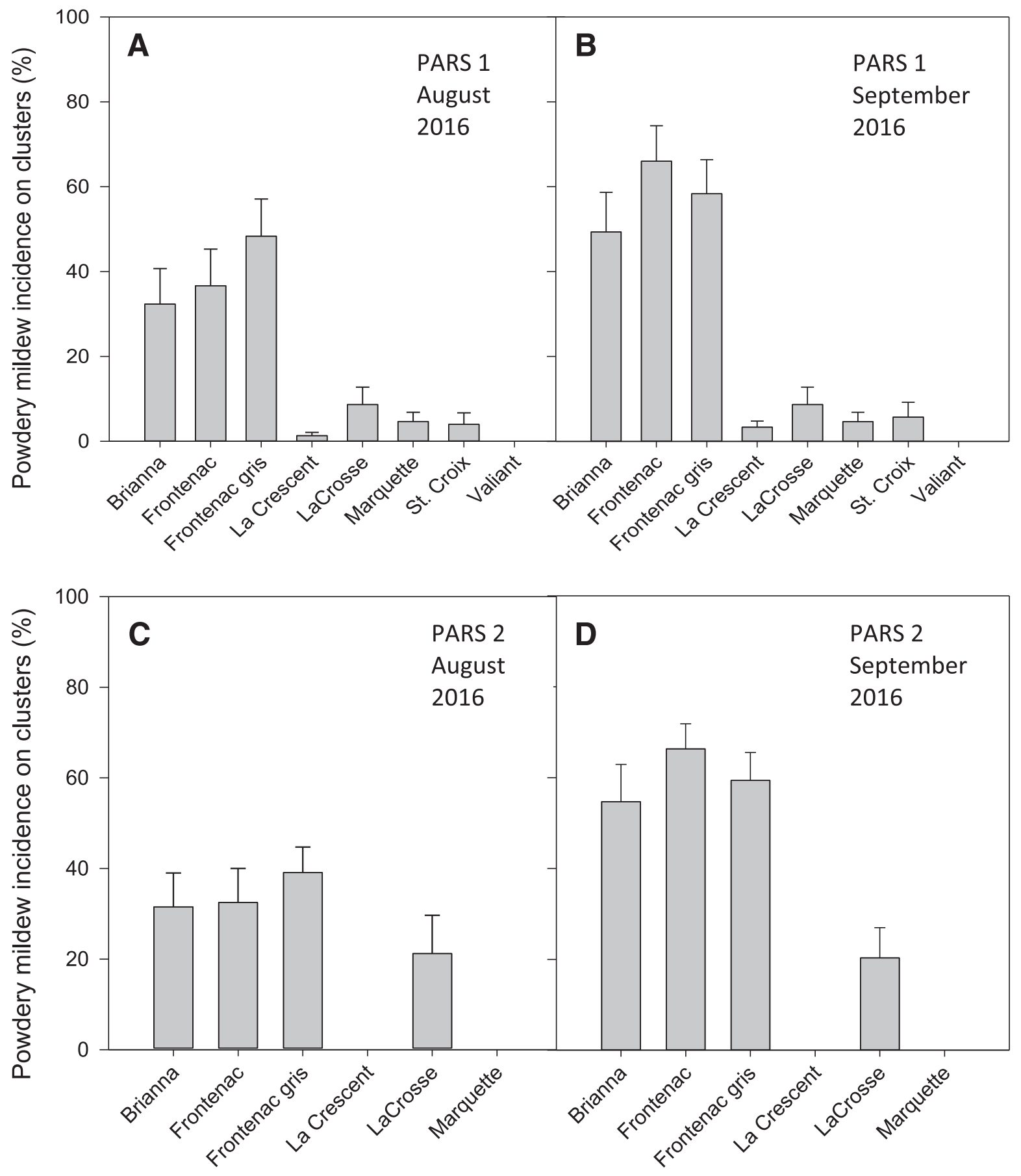

Fig. 3. Powdery mildew incidence on clusters (percent clusters diseased) at PARS 1 (A, B) and PARS 2 (C, D) in August and September 2016. 
critical to the growth, sustainability, and profitability of the coldclimate wine grape industry.

Across years and locations, there were consistent trends in the relative susceptibility of cultivars to foliar and fruit downy mildew (Fig. 1), allowing us to rank cultivars from most to least susceptible: Valiant $=$ LaCrosse $>$ La Crescent $>$ St. Croix $>$ Brianna $>$ Frontenac $=$ Frontenac gris $>$ Marquette. Downy mildew is capable of destroying fruit of many well-known cultivars of $V$. vinifera (Kassemeyer et al. 2015). Even when this disease does not directly destroy fruit, premature loss of foliage can cause fruit to fail to ripen (Kassemeyer et al. 2015). Our data suggest less risk for many of the cold-climate cultivars, even in the absence of fungicide applications. All of the cultivars that were included in this study, except Valiant, were resistant to downy mildew on fruit clusters, even when fruit were surrounded
A

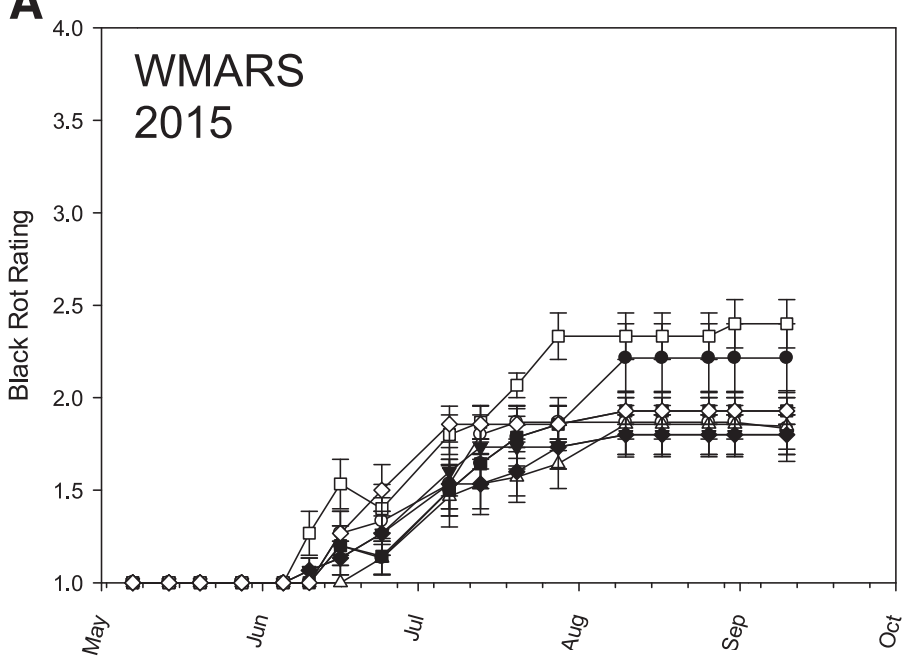

C

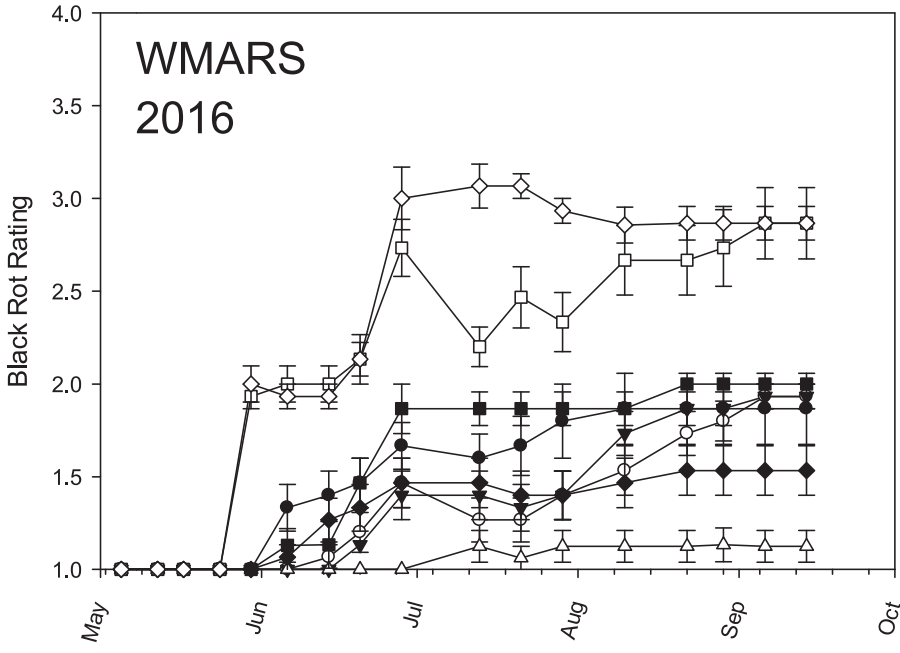

E

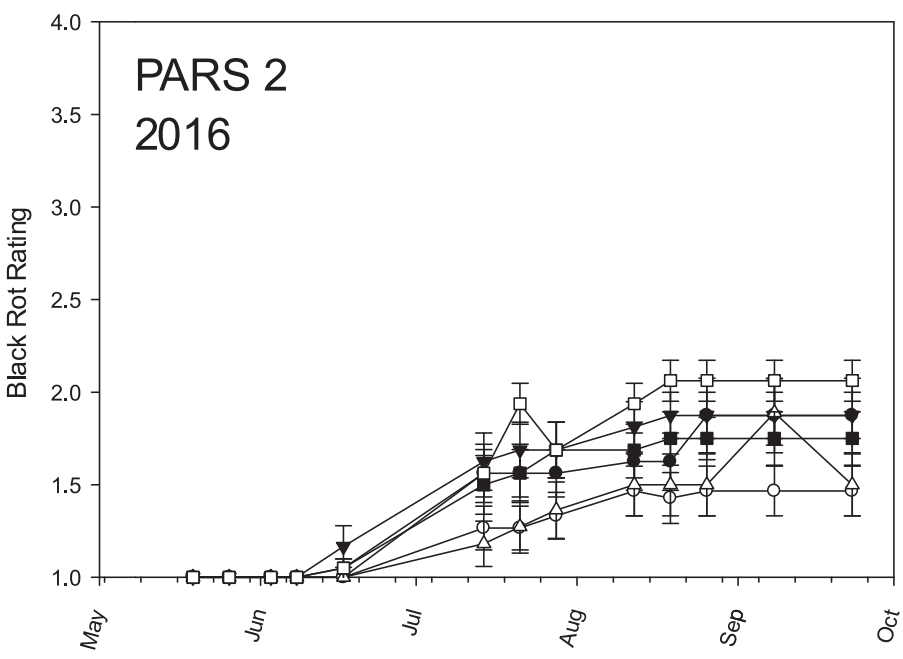

B

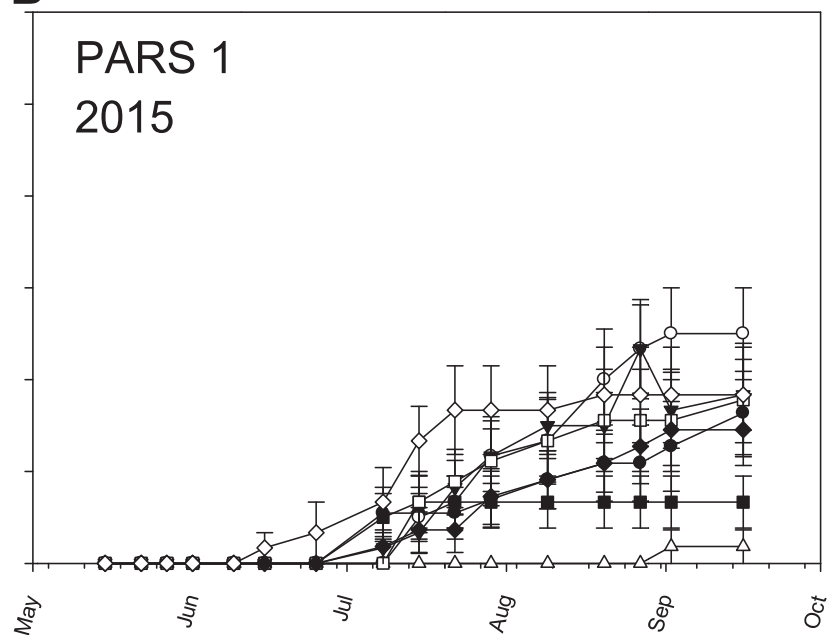

D

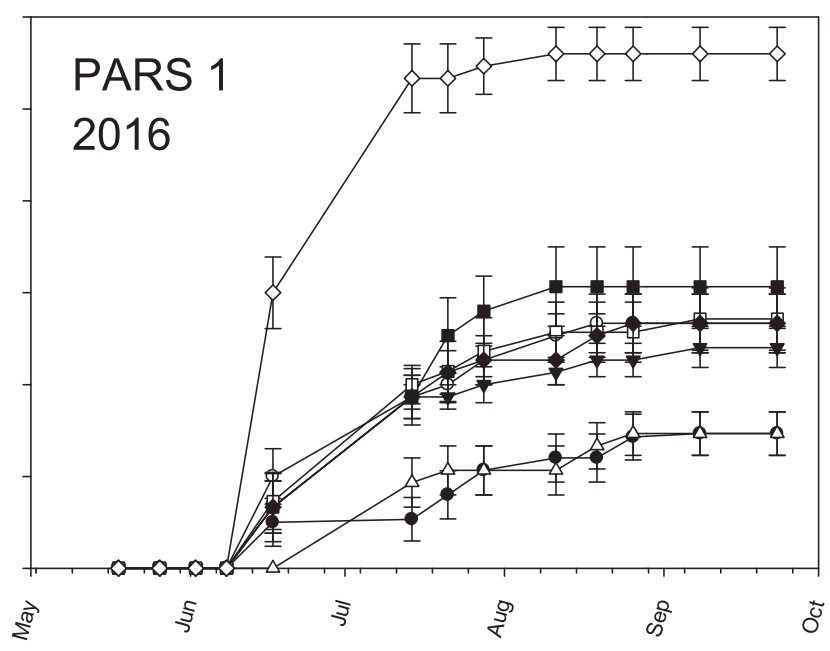

Fig. 4. Black rot severity ratings at WMARS, PARS 1, and PARS 2 in 2015 (A, B) and 2016 (C, D, E). In 2015, ratings were based on appearance of leaves and fruit clusters. In 2016, ratings were based on appearance of leaves only. 
by leaves with sporulating lesions during periods of rainy weather that were highly conducive to disease. Further, many cultivars showed delayed development of downy mildew and sustained only light or moderate foliar infection without a premature loss of leaves. Thus, on some cultivars, there is potential to reduce fungicide use substantially by foregoing sprays early in the season and focusing specifically on preventing defoliation in middle to late summer on an "as-needed" basis. Fewer sprays for downy mildew control would reduce costs to growers and would also reduce the risk for the development of fungicide resistance, a serious concern as resistance to quinone outside inhibitor (strobilurin) fungicides has already been documented in the grape downy mildew pathogen in several locations in the United States (Colcol and Boudoin 2016; Ward-Gauthier and Amsden 2014; Wong and Wilcox 2000).

Across years and locations, there were consistent trends in the relative susceptibility of cultivars to foliar and fruit powdery mildew (Figs. 2 and 3), allowing us to rank cultivars from most to least susceptible: Brianna $=$ Frontenac $=$ Frontenac gris $>$ Marquette $>$
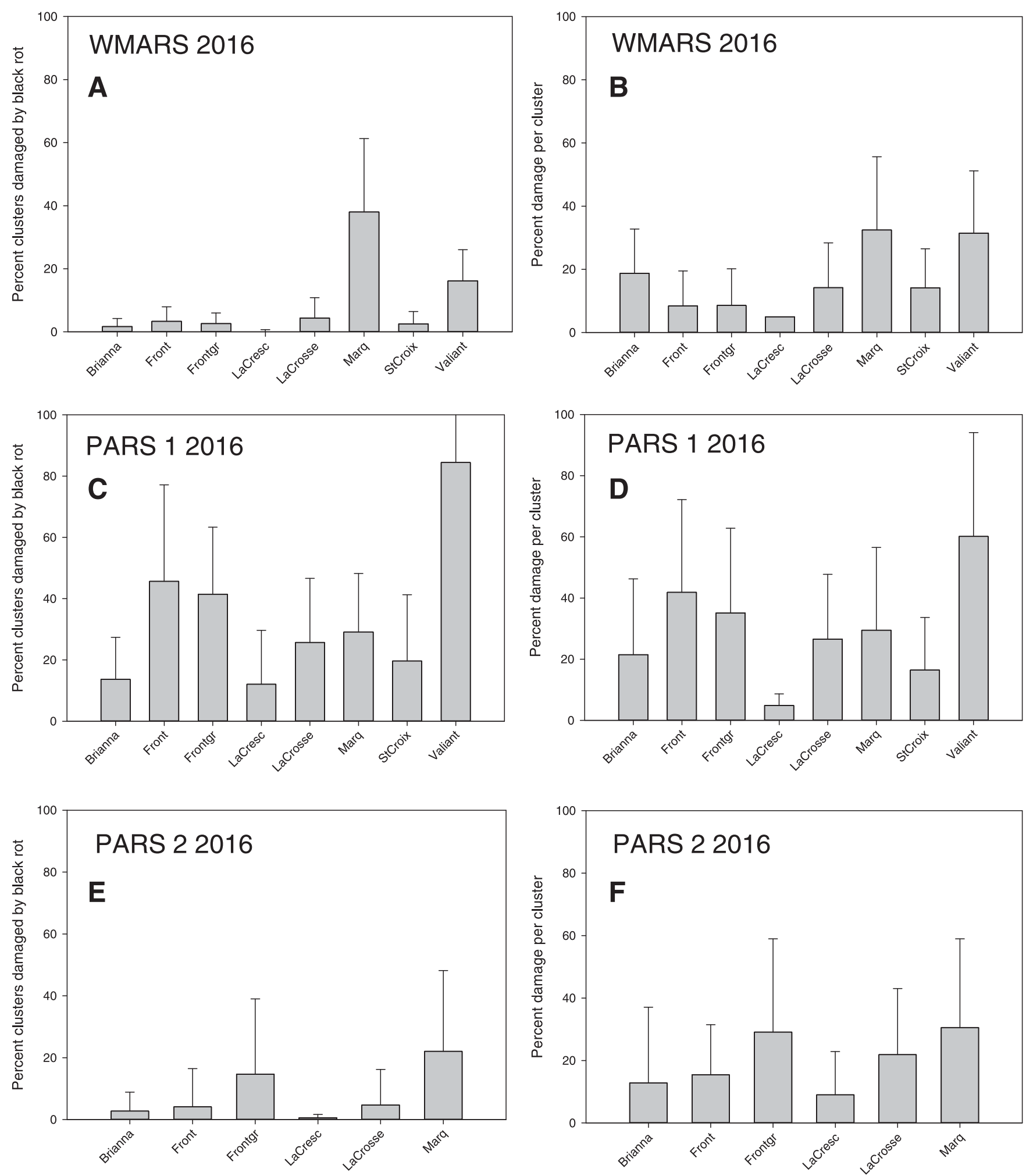

Fig. 5. Black rot A, C, and E, incidence on clusters (percent clusters diseased) and B, D, and F, severity (percentage of cluster area diseased) at WMARS, PARS 1, and PARS 2 in 2016. 
LaCrosse $>$ St. Croix $>$ La Crescent $=$ Valiant. Susceptibility to both fruit and foliar powdery mildew appears to be more common among the cold-climate cultivars than that observed for downy mildew and black rot, posing a potential challenge for the development of reduced-spray programs. Heavy powdery mildew damage can result in poor fruit ripening, uneven fruit sizing, fruit cracking, and loss of photosynthesis late in the season (Gadoury et al. 2015; Lakso et al. 1982). Our data suggest that future testing of reduced-spray programs may need to pay particular attention to powdery mildew, because this disease can cause significant direct damage to fruit and rachises of cold-climate cultivars. A possible confounding factor in our trials is the effect that one disease might have on another disease. For example, we observed low severity of powdery mildew on La Crescent and Valiant, but it is possible that extensive downy mildew damage to leaves made these cultivars less ideal hosts for powdery mildew. Because both the downy mildew and powdery mildew pathogens are obligate biotrophs, reduction of healthy leaf tissue by either pathogen could reduce the possibility of infection by the other. This might be addressed in future work by treating vines with a fungicide specific for either the downy mildew or powdery mildew pathogen, so that leaves remain healthy enough for the pathogen that is not controlled to infect and cause disease.

Across years and locations, there were consistent trends in the relative susceptibility of cultivars to foliar and fruit black rot (Figs. 4 and 5), allowing us to rank cultivars from most to least susceptible: Valiant $>$ Marquette $>$ Frontenac $=$ Frontenac gris $>$ Brianna $=$ LaCrosse $=$ St. Croix > La Crescent. Of the eight cultivars that were studied, foliar black rot was severe on only Valiant and Marquette, and even severely damaged vines were not defoliated prematurely by the disease. However, black rot caused severe damage to fruit on several cultivars despite low levels of foliar disease.

There was a significant increase in the severity of black rot in 2016 compared with 2015 at both WMARS and PARS 1, and also a greater degree of separation among the eight cultivars in 2016. This reflects the tendency of black rot inoculum to build up following a year of poor management. La Crescent was less susceptible to black rot compared with other cultivars, making it a possible candidate for organic vineyards, because fungicides approved for use in organic production are generally ineffective in controlling black rot (Weigle and Carroll 2016). By contrast, Marquette, Frontenac, Frontenac gris, and Valiant were all highly susceptible to black rot on fruit and moderately to highly susceptible to foliar black rot, making them more problematic choices for organic production.

Berries of V. labrusca and some interspecific hybrids have a window of peak susceptibility to black rot beginning at bloom and extending about 4 weeks after bloom (Hoffman and Wilcox 2002; Hoffman et al. 2004). Fruit mummies, particularly those that overwinter in the trellis, are a significant source of black rot inoculum (Hoffman and Wilcox 2002; Wilcox and Hoffman 2015). Peak ascospore release by these fruit mummies and the majority of infection periods occur during the 4-week window following bloom, and little ascospore release occurs after this time. Therefore, it may be possible to achieve good control of black rot in less-susceptible cold-climate cultivars with two or three sprays starting just before bloom and ending at 3 to 4 weeks after bloom if fruit mummies are removed each year prior to bloom.

Although the current study is the most systematic and comprehensive account of disease susceptibility in cold-climate wine grape cultivars, we acknowledge that the relatively small number of sites and years limits the conclusions that can be drawn. The cultivars tested here are grown over a large region encompassing the Great Plains, Midwest, and Northeast regions of the United States, where disease pressure might differ. Differences in temperature and precipitation between sites and years were likely a major source of variability in cultivars' performance in our trials, and these differences might be even more pronounced across a greater geographic range. Furthermore, 2 years may not be enough time to observe the long-term effects of
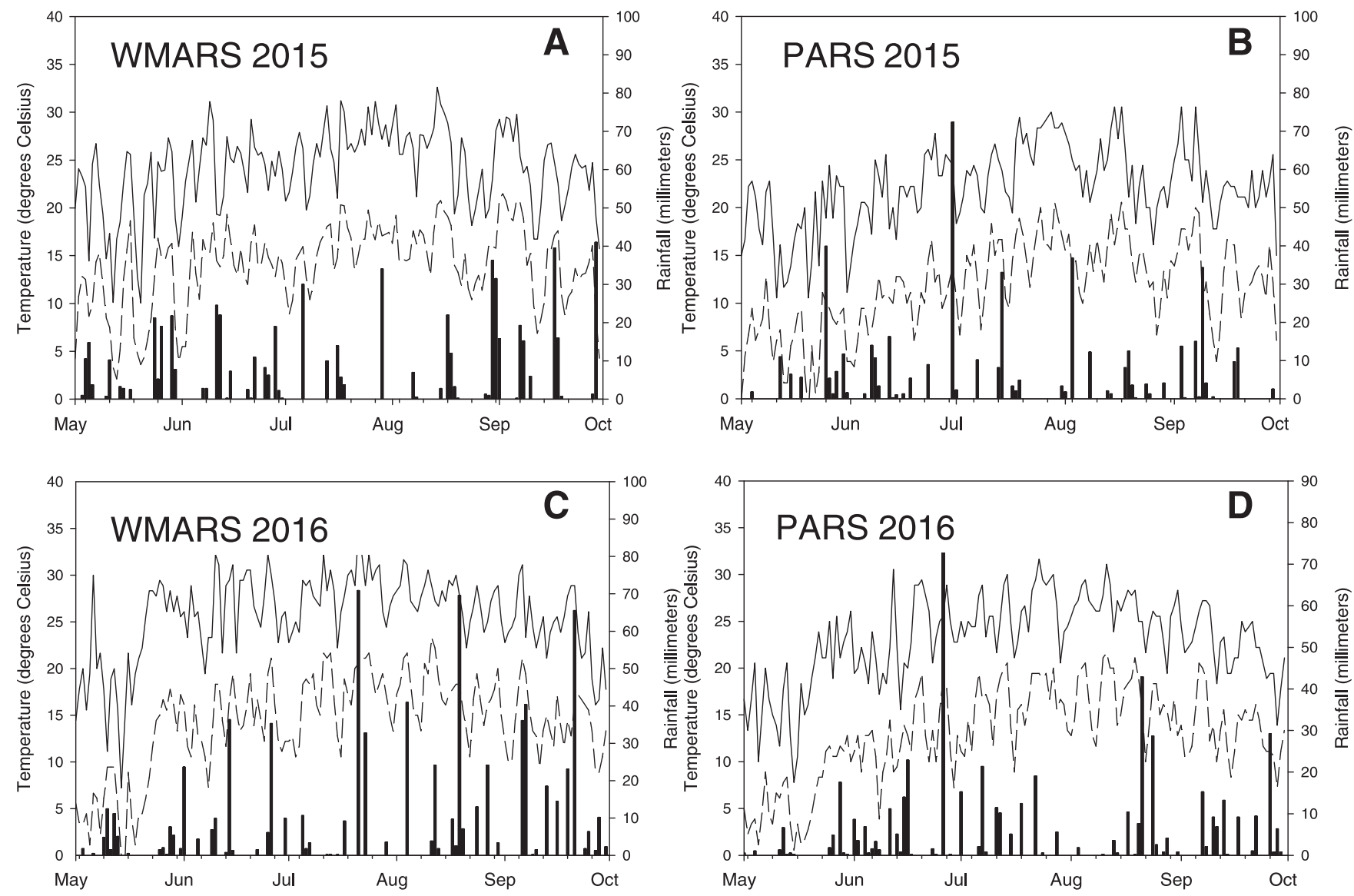

Fig. 6. Daily high temperature (degrees Celsius, solid line), daily low temperature (degrees Celsius, dashed line), and daily rainfall (millimeters, black bars) at WMARS, PARS 1 , and PARS 2 in 2015 (A, B) and 2016 (C, D). 
disease on cultivars in no-spray research trials or under reduced-spray programs in commercial vineyards. Both disease inoculum and the physiological effects of disease could build over time, particularly on moderately and severely susceptible cultivars, and this must be evaluated in future work. In particular, anthracnose, caused by the fungus Elsinoë ampelina, is reported to be a major threat to cold-climate wine grape production (Carisse and Lefebvre 2011; Carisse and Morissette-Thomas 2013); however, this disease was not observed in our study.

None of the eight cultivars included in this work were minimally susceptible to all three diseases (downy mildew, powdery mildew, and black rot). However, minimal susceptibility to one or two of these diseases in several cultivars provides the foundation for the development of spray programs tailored to specific cultivars. For example, Marquette was minimally susceptible to foliar downy mildew, and fruit were not susceptible to the disease. A program created specifically for this cultivar could eliminate sprays for downy mildew and instead focus on timely sprays for black rot and powdery mildew. A program with two to three sprays starting just before bloom and ending 4 to 5 weeks after bloom to control black rot (Hoffman and Wilcox 2002; Hoffman et al. 2004; Wilcox and Hoffman 2015) combined with spraying as needed for powdery mildew could provide acceptable disease management. Selection of fungicides that control both diseases simultaneously (e.g., strobilurins or sterol demethylation inhibitors) would enhance the efficiency and, possibly, the cost effectiveness of such a spray program.

Black rot is one of the most challenging diseases for organic growers to manage, because G. bidwellii is not highly sensitive to sprays containing copper (Bordelon et al. 2016; Weigle and Carroll 2016; Wilcox and Hoffman 2015). Therefore, organic spray programs may need to be developed using cultivars that are minimally susceptible to black rot. For example, La Crescent is minimally susceptible to black rot, displaying significantly lower levels of foliar and fruit damage than other cultivars in both 2015 and 2016. Additionally, La Crescent is minimally susceptible to powdery mildew. Although La Crescent is highly susceptible to downy mildew, copperbased fungicides provide excellent downy mildew control and are available to organic growers (Weigle and Carroll 2016). Although some grape cultivars are sensitive to injury from copper, La Crescent was sensitive in just 1 of 11 trials conducted over 4 years, and then only after six applications of copper hydroxide (McManus et al. 2017). Therefore, it is possible that two to three sprays of copper early in the growing season followed by spraying as needed for foliar downy mildew could be a viable strategy for organic production of La Crescent.

In summary, the aim of this study was to assess the disease susceptibility of cold-climate wine grape cultivars, so that host resistance can be factored into integrated disease management programs. Field studies to test reduced-spray or organic disease management programs such as those described above will have to focus not just on disease management but also on fruit quality, yield, and economics.

\section{Acknowledgments}

We thank J. Hedtcke and M. Stasiak and their teams at WMARS and PARS, respectively, as well as A. Cramer and $\mathrm{M}$. Hughan for help in the field; and P. Crump and D. Rouse for help with statistics. This work was funded by the USDA Specialty Crops Initiative Northern Grapes Project (award number 201151181-30850) and USDA Sustainable Agriculture Research and Education (project number GNC15-210).

\section{Literature Cited}

Bordelon, B., Beckerman, J., Bessin, R., Strang, J., and Weinzierl, R. 2016. Pages 93-100 in: Midwest Fruit Pest Management Guide. Purdue University Cooperative Extension Bulletin ID 465, West Lafayette, IN.

Carisse, O., and Lefebvre, A. 2011. Evaluation of northern grape hybrid cultivars for their susceptibility to anthracnose caused by Elsinö̈ ampelina. Online publication. Plant Health Prog. doi:10.1094/PHP-2011-0805-01-RS

Carisse, O., and Morissette-Thomas, V. 2013. Epidemiology of grape anthracnose: Factors associated with defoliation of grape leaves infected by Elsinoë ampelina. Plant Dis. 97:222-230.

Colcol, J. F., and Boudoin, A. B. 2016. Sensitivity of Erysiphe necator and Plasmopara viticola in Virginia to QoI fungicides, boscalid, quinoxyfen, thiophanate methyl, and mefanoxam. Phytopathology 100:337-344.

Gadoury, D. M., Wilcox, W. F., Rumbolz, J., and Gubler, W. D. 2015. Powdery mildew. Pages 75-83 in: Compendium of Grape Diseases, Disorders, and Pests, 2nd ed. W. F. Wilcox, W. D. Gubler, and J. K. Uyemoto, eds. American Phytopathological Society, St. Paul, MN.

Gartner, B. 2016. Northern grapes project surveys show growth. North. Grapes News. 5:8-10.

Hoffman, L. E., and Wilcox, W. F. 2002. Utilizing epidemiological investigations to optimize management of black rot. Phytopathology 92:676-680.

Kassemeyer, H. H., Gadoury, D. M., Hill, G., and Wilcox, W. F. 2015. Downy mildew. Pages 46-52 in: Compendium of Grape Diseases, Disorders, and Pests, 2nd ed. W. F. Wilcox, W. D. Gubler, and J. K. Uyemoto, eds. American Phytopathological Society, St. Paul, MN.

Lakso, A. N., Pratt, C., Pearson, R. C., Pol, R. M., Seem, R. C., and Welsner, M. J. 1982. Photosynthesis transpiration, and water use efficiency of mature grape leaves infected with Uncinula necator (powdery mildew). Phytopathology 72:232-236.

McManus, P. S., Kartanos, V., and Stasiak, M. 2017. Sensitivity of cold-climate wine grape cultivars to copper, sulfur, and difenoconazole fungicides. Crop Prot. 92:122-130.

Smiley, L.A., Domoto, P., and Nonnecke, G. 2015. Cold climate cultivars: A review of cold climate grape cultivars. Iowa State University Extension and Outreach Bulletin ID 3040-73, Ames, IA.

Tuck, B., and Gartner, W. 2013.Vineyards and grapes of the north: A status report. Online publication. University of Minnesota Extension Center for Community Vitality. http://www.extension.umn.edu/community/economic-impact-analysis/ reports/docs/2013-Vineyards-Grapes-North.pdf

Ward Gauthier, N. A., and Amsden, B. 2014. First report of QoI-Resistant downy mildew (Plasmopara viticola) of grape. Plant Dis. 98:276.

Weigle, T., and Carroll, J. 2016. Page 15 in: Organic Production and IPM Guide for Grapes. Publ. No. 224. New York State Integrated Pest Management Program, Ithaca, NY.

Wilcox, W. F., and Hoffman, L. E. 2015. Black rot. Pages 28-33 in: Compendium of Grape Diseases, Disorders, and Pests, 2nd ed. W. F. Wilcox, W. D. Gubler, and J. K. Uyemoto, eds. American Phytopathological Society, St. Paul, MN.

Wong, F. P., and Wilcox, W. F. 2000. Distribution of baseline sensitivities to azoxystrobin among isolates of Plasmopara viticola. Plant Dis. 84:275-281. 